\title{
Microstructure and Chemical Characterization of Copper Nanoparticles in Wood Dust by TEM/STEM
}

\author{
Chen Wang ${ }^{1}$, Chaolong Qi ${ }^{1}$, Alan K. Dozier ${ }^{1}$, Joseph E. Fernback ${ }^{1}$, and Pramod Kulkarni ${ }^{1}$ \\ 1. Division of Applied Research and Technology, National Institute for Occupational Safety and Health, \\ Cincinnati, OH, 45226, USA
}

In wood preservation industry, there is an increased use of particulate copper (i.e., micronized copper azole or MCA) preservative as a replacement for ionized copper preservative in pressure-treated lumber (PTL) [1]. The main components of MCA formulations include a micronized fraction of basic copper carbonate $\left(\mathrm{CuCO}_{3} \cdot \mathrm{Cu}(\mathrm{OH})_{2}\right)$ that can be released during the handling and processing of copper-treated wood [2,3]. This has raised concerns over the potential exposure of workers to the wood dust that contains micronized/nanoscale copper particles. A recent toxicity study indicated that sanding of coppertreated lumber can release nanoscale copper particles that are potentially cytotoxic. [4] By using TEM/STEM, the agglomerated and isolated copper nanoparticles were identified in the wood dust generated by sawing and sanding copper-treated lumber in a laboratory testing system [5]. In this study, we evaluated morphological and chemical properties of different types of copper-containing particles.

A laboratory testing system was customized to conduct automatic cutting and sanding in a ventilationcontrolled environment. A Thermophoretic Personal Sampler (TPS100) was used to collect dust samples on a 300 mesh carbon-coated nickel TEM grid. The TEM samples were analyzed with a JEOL 2100F TEM equipped with an Energy Dispersive X-ray Spectroscopy (EDS) detector. Bright Field (BF) and High Angle Annular Dark Field (HAADF) images were acquired in the Scanning Transmission Electron Microscopy (STEM) mode with a probe size of 0.5-1 nm. For the regions of interest (ROI), selected point analysis and line scans were performed to collect the EDS spectra for elemental identification. Three major elements in the particulate samples (carbon, copper and oxygen) were identified by their characteristic K lines. In addition, STEM spectrum images (STEM-SI) and Energy Filtered TEM (EFTEM) were used to analyze the elemental distributions at selected areas.

Results of the analyses of wood dust generated by cutting and sanding MCA treated PTL are shown in Figs. 1-3. Most of nanoscale copper particles were found embedded in the wood dust with sizes in the range from 5 to $1000 \mathrm{~nm}$. Free copper particles with average size of 100-200 nm were identified in pristine or oxidized forms, which indicated the potential chemical transformation of copper content. The microstructures of particles generated from different sample processing methods and testing conditions were also evaluated.

\section{References:}

[1] M. H. Freeman and C.R. Mcintyre, Forest Prod. J., 58 (2008), 6-27.

[2] C. Civardi, F. W.M.R. Schwarze and P. Wick, Environ. Pollut., 200 (2015), 126-132.

[3] W.E. Platten et al., Sci. Total Environ., 548 (2016), 441-449.

[4] J. D. Sisler et al., J. Occup. Environ. Hyg., (2018), accepted.

[5] C. Wang et al., Microsc. Microanal. 22 (2016), 1892. 

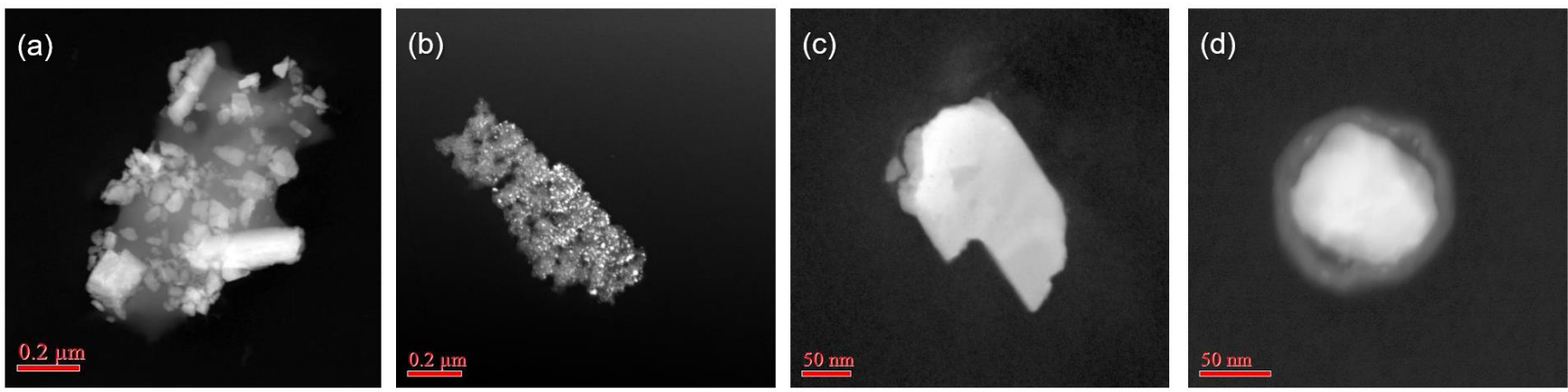

Figure 1. STEM-HAADF images of four types copper-containing particles released during the sawing or sanding of MC treated lumber: (a) wood dust with embedded microscale copper particles; (b) wood dust with embedded copper particles; (c) free copper particle; (d) free copper particle with a core-shell structure.
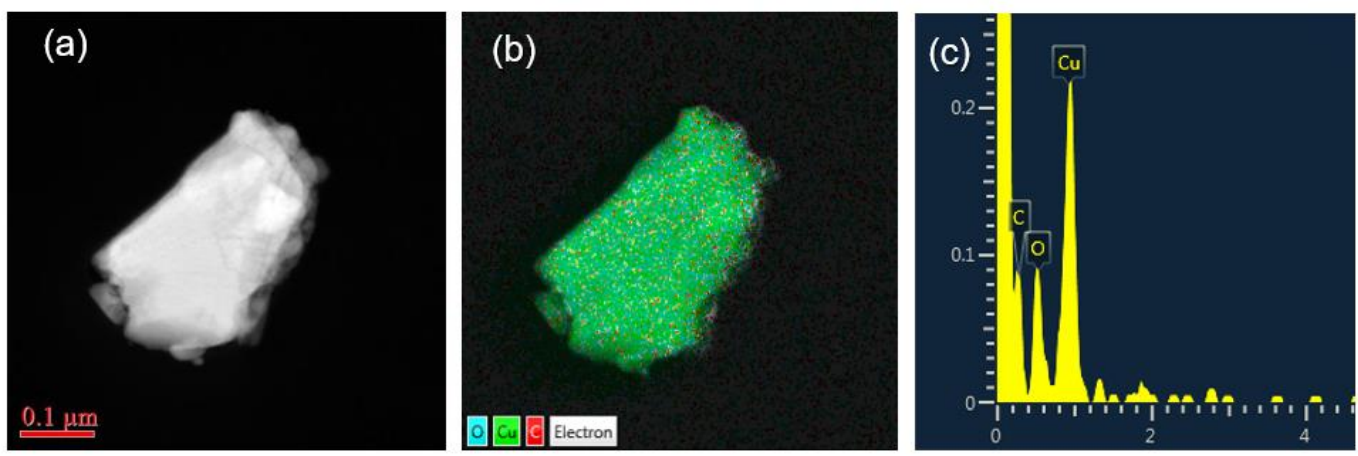

Figure 2. STEM-HAADF image of a free copper particle and corresponding EDS map and spectrum showing the presence of $\mathrm{Cu}, \mathrm{O}$ and $\mathrm{C}$.
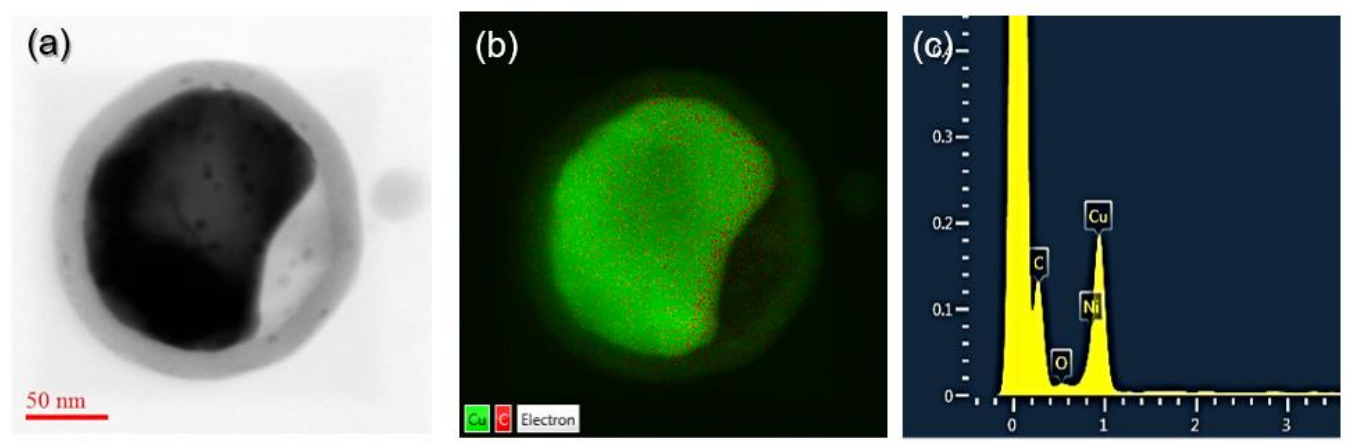

Figure 3. STEM-BF image of a free copper particle and corresponding EDS map and spectrum showing the presence of $\mathrm{Cu}$ and $\mathrm{C}$. 